\title{
Major Lipid Body Protein: A Conserved Structural Component of Lipid Body Accumulated during Abiotic Stress in S. quadricauda CASA-CC202
}

\section{OPEN ACCESS}

\section{Edited by:}

Peer Schenk,

University of Queensland, Australia

Reviewed by:

Yu-Shen Cheng,

National Yunlin University of Science and Technology, Taiwan Jaime Puna

Instituto Superior de Engenharia de Lisboa, Portugal Ihsan Hamawand, University of Southern Queensland, Australia

*Correspondence: Muthu Arumugam arumugam@niist.res.in, aasaimugam@gmail.com

${ }^{\dagger}$ Anand Javee and Sujitha Balakrishnan Sulochana are joint first authors and contributed equally.

Specialty section: This article was submitted to Bioenergy and Biofuels, a section of the journal Frontiers in Energy Research

Received: 18 May 2016 Accepted: 01 November 2016 Published: 23 November 2016

Citation: Javee A, Sulochana SB, Pallissery SJ and Arumugam M (2016) Major Lipid Body Protein: A Conserved Structural

Component of Lipid Body Accumulated during Abiotic Stress in S. quadricauda CASA-CC202.

Front. Energy Res. 4:37. doi: 10.3389/fenrg.2016.00037

\author{
Anand Javee ${ }^{1 \dagger}$, Sujitha Balakrishnan Sulochana ${ }^{1,2+}$, Steffi James Pallissery ${ }^{1}$ and \\ Muthu Arumugam ${ }^{1,2 *}$
}

${ }^{1}$ Biotechnology Division, National Institute for Interdisciplinary Science and Technology (NIIST), Council of Scientific and Industrial Research (CSIR), Trivandrum, India, ${ }^{2}$ Academy of Scientific and Innovative Research (AcSIR), New Delhi, India

Abiotic stress in oleaginous microalgae enhances lipid accumulation, which is stored in a specialized organelle called lipid droplets (LDs). Both the LDs or lipid body are enriched with major lipid droplet protein (MLDP). It serves as a major structural component and also plays a key role in recruiting other proteins and enzymes involved in lipid body maturation. In the present study, the presence of MLDP was detected in two abiotic stress condition namely nitrogen starvation and salt stress condition. Previous research reveals that nitrogen starvation enhances lipid accumulation. Therefore, the effect of salt on growth, biomass yield, and fatty acid profile is studied in detail. The specific growth rate of Scenedesmus quadricauda under the salt stress of $10 \mathrm{mM}$ concentration is about $0.174 \mu$ and in control, the SGR is $0.241 \mu$. An increase in the doubling time of the cells shows that the rate of cell division decreases during salt stress (2.87-5.17). The dry biomass content also decreased drastically at 50mM salt-treated cells (129 mg/L) compared to control ( $236 \mathrm{mg} / \mathrm{L})$ on the day 20 . The analysis of fatty acid composition also revealed that there is a $20 \%$ decrease in the saturated fatty acid level and $19.9 \%$ increment in monounsaturated fatty acid level, which makes salt-mediated lipid accumulation as a suitable biodiesel precursor.

Keywords: major lipid droplet protein, Scenedesmus quadricauda, abiotic stress, nitrogen deprivation, salt stress, FAME profile

\section{INTRODUCTION}

Microalgae are unicellular photosynthetic organisms, gaining importance as a feedstock for high-value nutraceuticals, bioactive compounds, and biodiesel. The microalgae have various advantages over other organisms due to its fast growth rate, ability to adapt to varying environmental condition, can be cultured in a season-independent manner, and do not compete with the inputs deployed for agriculture. Oleaginous microalgae accumulate the lipid in the form of triacylglycerol (TAG) in distinct organelles called lipid droplets (LDs) located in the cytoplasm.

Abbreviations: BBM, bold basal medium; FAME, fatty acid methyl ester; FITC, fluorescein iso thio cyanate; LD, lipid droplets; MLDP, major lipid droplet protein; PBS, phosphate buffer saline; SGR, specific growth rate; TAG, triacylglycerol; TDS, total dissolved solids; TLC, thin layer chromatography. 
The increased level of LDs was observed during abiotic stresses, such as nutrient deprivation and high light exposure, in microalgae. As a result, they gained an attention in exploring as a source for high-value edible oil or renewable transportation fuel (Moellering and Benning, 2010). Like microalgae, plants also store oil in specialized compartments known asLDs, oil bodies/ globules or oleosomes. The neutral storage lipids (mainly TAGs) are stored in these spherical organelles enclosed by a membrane lipid monolayer coated with proteins (Davidi et al., 2012).

Major lipid droplet protein (MLDP) is found in lipid bodies. The MLDP forms a proteinaceous coat surrounding mature LDs. The characterization of LD proteins has been reported in terrestrial oil seed plants and in certain mammalian tissues (Zweytick et al., 2000; Murphy et al., 2001). Downregulation of MLDP through RNA interference affects LD size without any compromise in the TAG level or its metabolism in Chlamydomonas reinhardtii (Moellering and Benning, 2010). Similarly, LDs' size and number vary while silencing or knocking down of oleosin in oleaginous plants (Siloto et al., 2006; Schmidt and Herman, 2008). MLDP stabilizes mature LDs and acts as a recruiting platform for other proteins and enzymes required for the maturation of LDs. In C. reinhardtii, MLDP is identified as an abundant protein on the outer surface of the LDs proteome (Moellering and Benning, 2010; Nguyen et al., 2011). MLDP abundance positively correlates with the accumulation of TAGs (Tsai et al., 2014). During nitrogen starvation, both MLDP and TAG were over accumulated, and the inhibition of TAG biosynthesis impairs MLDP level, suggesting that MLDP induction is coregulated with TAG accumulation in Dunaliella (Davidi et al., 2012). Besides MLDP being a major structural protein of LDs proteome, it also contains many regulatory enzymes, such as acyl-activating enzymes, acyl transferase, or lipases, involved in lipid biosynthesis as well as the maturation of LDs (Huang, 1992; Brown, 2001; Athenstaedt and Daum, 2006).

Although the plant oleosins and animal perilipins are well characterized, the structure and function of the green algal MLDP are still not clear. MLDP has been reported in green algal lineages, such as Chlorella vulgaris, Volvox carteri, Dunaliella salina, and Haematococcus pluvialis, however not mapped in diatoms, red algae, or seed plants for which sequenced genomes are available (Moellering and Benning, 2010; Peled et al., 2011; Davidi et al., 2012). D. salina MLDP shares high homology with conserved proline-rich domain in C-terminal end of green algal linage. In addition, MLDP expression also correlated with the high-lipid accumulation (Davidi et al., 2012). Multiple sequence alignment of major oil globule proteins from Dunaliella, C. reinhardtii, and H. pluvialis revealed the consistence of 21 amino acids conserved motif, with four proline residues close to the $\mathrm{C}$-terminal end. MLDP of green algae does not show any sequence homology to plant oleosins, to mammalian perilipins, and not even to diatoms or to any other alga whose genome is sequenced, suggesting that MLDPs are unique to the green algal lineage (Davidi et al., 2012).

In this present study, we made an attempt to detect the presence of MLDP in Scenedesmus quadricauda CASA-CC202 (KM250077) exposed to two practically feasible abiotic stress conditions namely, nitrogen starvation and salt stress. Since
Scenedesmus genome sequence is not available, the MLDP cloning and its bio characterization or its antibody is not available. Therefore, we have used the other closely related to green microalgae $C$. reinhardtii MLDP antibody to validate the presence of MLDP during the abiotic stress condition. The results reveal that MLDP of C. reinhardtii cross-react with Scenedesmus MLDP as evident from the confocal images. In concurrence with the increment of MLDP, the current work envisioned to investigate the lipid yield and its associated attributes, such as cell number, specific growth rate, total biomass yield, photosynthetic pigments, and fatty acid composition during salt stress and nitrogen stress. The effect of nitrogen stress triggered lipid accumulation and other parameters were described by Anand and Arumugam (2015). Recently, we have demonstrated that during nitrogen starvation Scenedesmus leads to 2.27-fold more lipid accumulation with enlarged cell size. In addition to that, a decrease in protein synthesis, photosynthetic pigments, arrest in cell division, morphological change, and enlarged LDs were also observed during nitrogen-starved condition (Anand and Arumugam, 2015). Also, stress-responsive hormone abscisic acid (ABA) shoots up during nitrogen starvation within $24 \mathrm{~h}$, and the level is falling down subsequently. ABA under nitrogen starvation has played an important role to cope-up the stress and adaptation to the stress environment (Sulochana and Arumugam, 2016). In the present study, the effect of salt on cell number, dry biomass, total lipid yield, and its fatty acid composition are discussed in detail. In general, MLDP a structural protein found in surface of lipid bodies of oleaginous microalgae, no information was reported for $S$. quadricauda, thus the present work aims to show the proof that MLDP indeed present in S. quadricauda during nitrogen and salt stress, the general stress condition applied to enhance the lipid yield.

\section{MATERIALS AND METHODS}

\section{Strain, Growth Conditions, and Salt Stress Induction}

The S. quadricauda CASA-CC202 (KM250077) cultures were grown in optimized conditions as described by Anand and Arumugam, 2015. The algal cells were grown at $25 \pm 2{ }^{\circ} \mathrm{C}$ with 14:10 h light-dark period. The flasks were gently shaken twice daily to avoid adherence of the cells to the walls, and there was no air and $\mathrm{CO}_{2}$ was supplemented during the experimental period. The salt stress was induced when the cells grown to its log phase harvested by centrifugation (10000 rpm for $10 \mathrm{~min}$ ), and the pellets were washed with double distilled water. Then the pellets were transferred to the stress media with different $\mathrm{NaCl}$ concentration $(10-50 \mathrm{mM})$, and subsequently, the nitrogen stress was induced (Sulochana and Arumugam, 2016).

\section{Immunostaining of Scenedesmus quadricauda MLDP}

The experimental algal cells were prefixed with $4 \%$ paraformaldehyde, subsequently, the fixed cells were suspended with sensitization solution composed of $0.1 \mathrm{M}$ Tris-7.5, $0.15 \mathrm{M} \mathrm{NaCl}$, and $0.1 \%$ Triton X-100 for $30 \mathrm{~min}$. Sensitized cells were washed 
twice with $0.1 \mathrm{M}$ Tris-7.5 with $0.1 \%$ Triton X-100 in the same tube. MLDP polyclonal antibody was added in 1: 1000 dilution ratio, and incubated for $3 \mathrm{~h}$ in rocker at $4^{\circ} \mathrm{C}$. Cells were washed thrice with wash solution followed by incubation with secondary antibody (anti-rabbit antibody) conjugated with FITC for two more hours. The cells were washed three times and suspended in $1 \times$ PBS and viewed under a confocal microscope.

\section{Growth Characteristics and Biomass Yield under Salt Stress}

At every 5-day interval, the samples were drawn aseptically from the stressed and control flasks, and the growth was measured spectrophotometrically at $540 \mathrm{~nm}$. Cell number, a direct microscopic enumeration, was performed at every 5-day intervals as described in Anand and Arumugam (2015). The specific growth rate was measured, number of generation (doubling time), that occurs per unit of time in an exponentially growing culture. The phase of growth was carefully determined, and the specific growth rate was obtained using the following equation (Guillard and Ryther, 1962).

$$
\mu=\operatorname{Ln}\left(N_{\mathrm{t}} / N_{0}\right) / T_{\mathrm{t}}-t_{0}
$$

$N_{\mathrm{t}}=$ number of cells at the end of the log phase; $N_{0}=$ number of cells at the start of $\log$ phase; $T_{\mathrm{t}}=$ final day of log phase; and $T_{0}=$ starting day of log phase. If $T$ expressed in days from the growth rate $(\mu)$ can be converted to division or doubling per day $(K)$ by dividing $(\mu)$ by the natural $\log$ of $2(0.6931)$. In order to determine the dry biomass yield, $10 \mathrm{ml}$ samples were filtered on to pre-dried and weighed GF/C fiber filters every third day of intervals. The filtered biomasses were oven dried overnight at $60^{\circ} \mathrm{C}$ along with filter paper, and reweighed using an analytical balance. The dry biomass of Scenedesmus under salt stress condition was expressed in grams per liter.

\section{Estimation of Total Lipids}

Total lipid was estimated by Folch et al. (1957) method for different $\mathrm{NaCl}$-treated $S$. quadricauda. In brief, $5 \mathrm{ml}$ of culture was taken from $400 \mathrm{ml}$ sample in a $1000 \mathrm{ml}$ Erlenmeyer flask. The biomass was collected by centrifugation at $10000 \mathrm{rpm}$ for $10 \mathrm{~min}$ and suspended in $6 \mathrm{ml}$ of chloroform:methanol (2:1) for $5 \mathrm{~h}$, then $2 \mathrm{ml}$ of $0.9 \%$ saline was added and mixed vigorously, and incubated for $12 \mathrm{~h}$. From the lipid-containing lower phase, $0.5 \mathrm{ml}$ was pipetted out and transferred to a fresh $2 \mathrm{ml}$ Eppendorf tube and allowed for evaporation. After that, $0.5 \mathrm{ml}$ of concentrated sulfuric acid was added and mixed well, and the tubes were kept in a water bath for $15 \mathrm{~min}$ and cooled to room temperature. From that, $0.2 \mathrm{ml}$ was pipetted out and transferred to the fresh test tube containing $5 \mathrm{ml}$ of vanillin reagent, was mixed well, and incubated for $20 \mathrm{~min}$ at room temperature. After incubation, the appearance of pink color indicates the presence of lipid, and then the sample was read at $520 \mathrm{~nm}$.

\section{Estimation of Total Chlorophyll Pigments}

The total photosynthetic algal sample was taken and centrifuged at $8000 \mathrm{rpm}$ for $10 \mathrm{~min}$ and the supernatant was discarded. Then, the pellet was resuspended in the $100 \%$ acetone, sonicated for $2 \mathrm{~min}$, and covered with aluminum foil and kept at $4^{\circ} \mathrm{C}$ for overnight. The next day, it was centrifuged for $10 \mathrm{~min}$ at $8000 \mathrm{rpm}$ and the supernatant was collected in a fresh test tube and the reading was taken at subsequent wavelength. The supernatant was collected, and its optical density was measured and recorded at $644.8 \lambda, 661.6 \lambda$, and $470 \lambda$ in UV-Visible spectrophotometer (Lichtenthaler, 1987).

\section{Scanning Electron Microscopy}

The salt-stressed algal cells were withdrawn at day 20 time point, and the algal cells were centrifuged at $8000 \mathrm{rpm}$ for $5 \mathrm{~min}$. Cell pellets were fixed using a fixative containing $2.5 \%$ glutaraldehyde and $2 \%$ paraformaldehyde in $0.1 \mathrm{M}$ sodium phosphate ( $\mathrm{pH} 7.0$ ). Scanning electron micrographs were captured using a Scanning Electron microscope operating at $100 \mathrm{kV}$.

\section{Lipid Extraction, Transesterification, and FAME Analysis}

Cells were filtered after harvesting with GC filter paper; the pellet was dried in an oven overnight at $80^{\circ} \mathrm{C}$ for drying. From that, $1 \mathrm{~g}$ of dry algal biomass was processed further for total lipid extraction method. $1 \mathrm{~g}$ of dried algal biomass was suspended in $200 \mathrm{ml}$ of chloroform:methanol (2:1), with $500 \mathrm{ml}$ round bottom flask. This setup ran with soxhlet apparatus, for $12 \mathrm{~h}$. Afterward, within the solvent mixture $40 \mathrm{ml}$ of $0.9 \%$ saline solution was added, mixed well, and allowed for phase separation. The lipidcontaining lower phase was collected in fresh beaker and washed well with methanol and water (1:1) ratio and allowed for phase separation to occur in separating funnel. Lipid-containing lower phase was collected in pre-weighed glass container and kept at room temperature to remove the residual solvent. The lipid yield was quantified gravimetrically, and the same was subjected to TLC or Gas chromatography (Folch et al., 1957; Cristie, 1982).

The total lipid sample was resolved by TLC along with appropriate standards. The transesterification of total lipid was performed as described by Marinkovic and Tomasevic (1998), with little modification. In brief, the cell pellet was re-suspended in $5 \%$ of sulfuric acid and methanol $(\mathrm{V} / \mathrm{V})$, followed by vigorous vortex for $30 \mathrm{~s}$, and kept in a water bath for $2 \mathrm{~h}$ at $90^{\circ} \mathrm{C}$, then allowed to cool. $1.5 \mathrm{ml}$ of $0.9 \%$ saline solution (w/v) was added to the cooled mixture followed by $1 \mathrm{ml}$ of hexane, vortexed well. The resulting mixture was centrifuged briefly and the upper hexane phase was transferred to a fresh tube. The resulting hexane containing FAME was sequentially washed with sodium bicarbonate followed by water and dissolved using anhydrous sodium sulfate. The dried sample was dissolved in hexane, and fatty acid profile was analyzed by gas chromatography (Su et al., 2011; Xin et al., 2011; Anand and Arumugam, 2015).

\section{RESULTS AND DISCUSSION}

\section{Conservation of MLDP in Green Microalgae}

The LD mainly comprises a globular neutral lipid core surrounded by a membrane lipid monolayer and it is highly conserved in different species (Murphy et al., 2001). A recent study of LDs 
in C. reinhardtii showed the abundance of MLDP (Moellering and Benning, 2010; James et al., 2011). The phylogenetic analysis shows that algal MLDP was highly conserved among the aligned sequence of Dunaliella, $H$. pluvialis, C. reinhardtii, and V. carteri (Davidi et al., 2012). The secondary structure prediction of MLDP shows that they are highly structured $\alpha$-helices and a short unstructured domain toward the C-terminal end (Guermeur et al., 1998). MLDP comprises a highly conserved motif prolinerich domain of about 21 amino acids in their C-terminal end. All the known MLDPs have two hydrophobic stretch first at 30 and 50 and the second region between 150 and 250 amino acid residues. Even though it is well studied in other green algae, the presence of MLDP, or like proteins was not yet elucidated in S. quadricauda being a suitable strain of biofuel application. The current study confirms the presence of MLDP-like protein conserved in S. quadricauda genome.

\section{Detection of MLDP during Abiotic Stress-Immunostaining}

Major lipid droplet protein was found out to be the most abundant protein in C. reinhardtii (Moellering and Benning, 2010; Nguyen et al., 2011). Tsai et al. (2014) have reported that MLDP abundance positively correlates with the TAG accumulation, indicating the coregulation of LD and TAG. On the other hand, the lipid MLDP-RNAi silenced lines show about $40 \%$ increased LD size in C. reinhardtii under nitrogen-starved condition (Moellering and Benning, 2010). Collectively, in microalgae LD formation, maturation during abiotic stress is tightly regulated through MLDP and its associated partners. Not much information available for S. quadricauda, regarding the presence of MLDP and its abundance during the nitrogen starvation or salt stress condition.
Here, we report that $C$. reinhardtii MLDP polyclonal antibody (Huang et al., 2013) recognizes and cross-react with the $S$. quadricauda MLDP, indicating the presence and conservation of MLDP-like protein in green microalga linage (Figure 1). Additionally, we also tested the relative abundance of MLDP in two important stress conditions like nitrogen starvation and salt stress condition; confocal imaging reveals the accumulation of MLDP in both the stress condition (Figure 1). Evolutionally, MLDP or MLDP-like proteins are functionally conserved among green microalgae. However, it is interesting to investigate more about the regulation of MLDP-like protein and its other partners in lipid body maturation during abiotic stress.

\section{Influence of Salt Stress on Cell Growth in S. quadricauda}

The increase in salt concentration exhibits negative effects on the growth of $S$. quadricauda. The maximum cell density occurs in the control (0.583) (BBM medium having $0.43 \mathrm{mM}$ salt concentration) and in $10 \mathrm{mM}(0.451)$ salt-treated cells. Increasing concentrations of salt $(30,40$, and $50 \mathrm{mM})$ lead to a significant amount of reduction in cell density. A similar effect was also observed in the case of cell number. The maximum cell numbers were recorded at $715 \times 10^{4}$ cells $/ \mathrm{ml}$ in control, followed by 10 and $20 \mathrm{mM} \mathrm{NaCl}$ concentration with 497 and $391 \times 10^{4}$ cells $/ \mathrm{ml}$, respectively (Figure 2).

Similarly, Hyder and Greenway (1965) found out that salinity arrests the growth of microalgae. The salt-tolerant studies on C. vulgaris by Talebi et al. (2013) show decrement in growth and moderate resistance up to $0.5 \mathrm{M} \mathrm{NaCl}$ concentration. Also, salinity more than $0.1 \mathrm{M}$ completely inhibited the growth of C. emersoni,
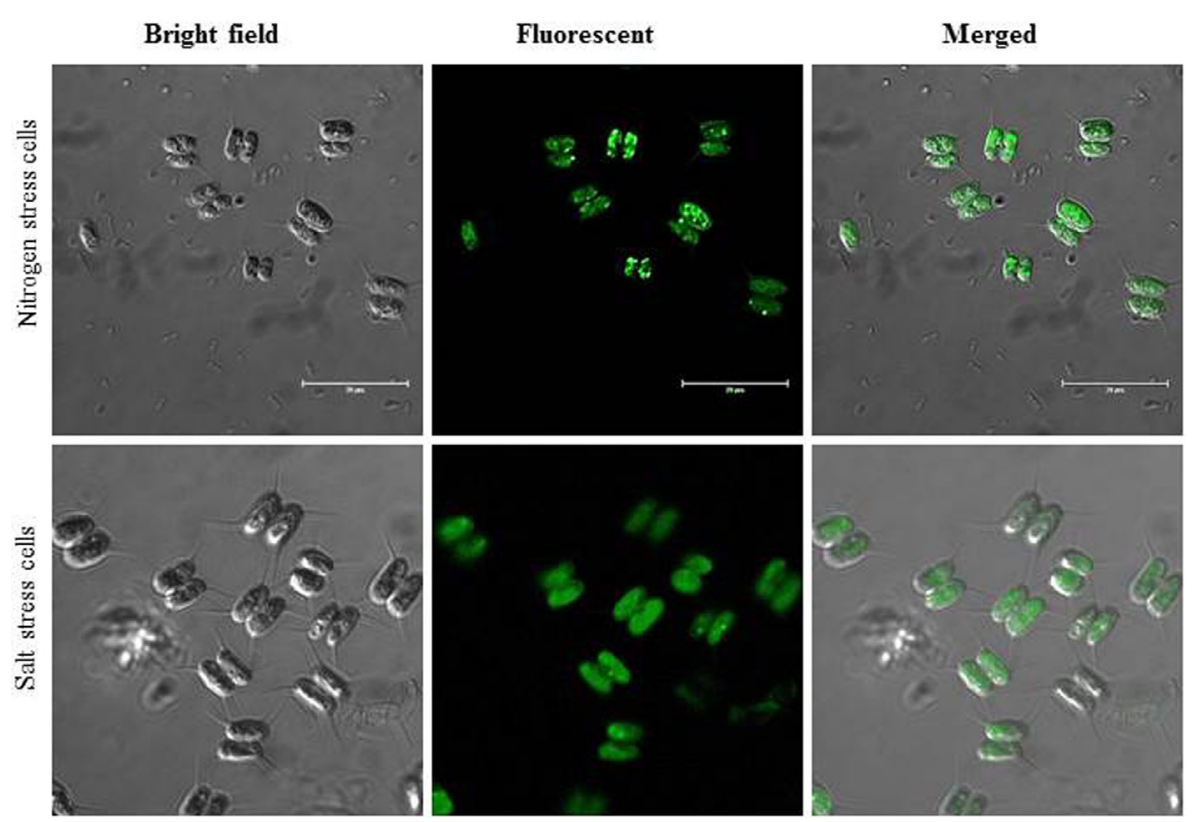

FIGURE 1 | Immunostaining lipid body structural protein fluorescent images under nitrogen-starved and salt stress cells. Scale bar represent 20 $4 \mathrm{~m}$ in each panel. 
and cell density and biomass becomes completely vanished during prolonged stress.

The control S. quadricauda sample had significant SGR compared to higher $\mathrm{NaCl}$-treated sample (0.241-0.134), respectively. An increase $(30,40,50 \mathrm{mM})$ in the $\mathrm{NaCl}$ concentration showed a decline in the SGR and doubling/d $(K)$ occurred in the culture (0.134-0.193), respectively (Table 1). Although the doubling time under salt stress is negatively correlated with the SGR, there was a raise in doubling time $(4.98,5.02,5.17)$ in the all higher $(30,40$, $50 \mathrm{mM}) \mathrm{NaCl}$ concentration, respectively. Whereas control had very short doubling time $(2.87)(\mathrm{Tt})$ compared to other higher $(30,40,50 \mathrm{mM}) \mathrm{NaCl}$ concentration (Table 1).

\section{Effect of Salt Stress on Biomass of S. quadricauda}

The $S$. quadricauda biomass content was considerably higher at the salinities of control $(0.43 \mathrm{mM})$ and $10 \mathrm{mM}$ compared to 40 and $50 \mathrm{mM} \mathrm{NaCl}$ concentration. The maximum dry biomass content of S. quadricauda was obtained of about $236 \mathrm{mg} / \mathrm{L}$ dry biomass in 20th day in control, whereas in $50 \mathrm{mM} \mathrm{NaCl}$ concentration the biomass content of 20th day obtained at the $129 \mathrm{mg} / \mathrm{L}$

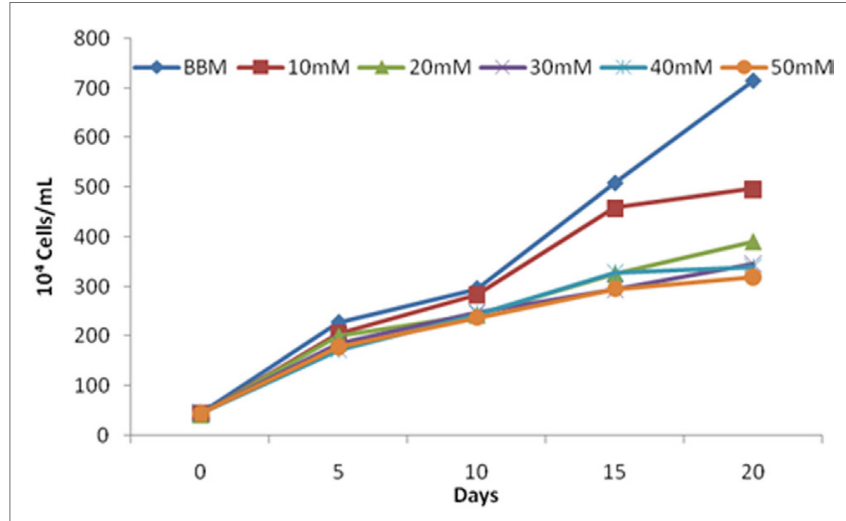

FIGURE 2 | Scenedesmus quadricauda cell numbers under salt stress condition. Each bar represent different concentration of salt levels.

TABLE 1 | Specific growth rate of S. quadricauda under different Salt stress.

\begin{tabular}{lclllll}
\hline & Control & $\mathbf{1 0} \mathbf{m M}$ & $\mathbf{2 0} \mathbf{m M}$ & $\mathbf{3 0} \mathbf{m M}$ & $\mathbf{4 0} \mathbf{m M}$ & $\mathbf{5 0 m M}$ \\
\hline Specific growth rate $(\mu)$ & 0.241 & 0.174 & 0.161 & 0.139 & 0.138 & 0.134 \\
Doubling/day $(K)$ & 0.348 & 0.253 & 0.233 & 0.201 & 0.200 & 0.193 \\
Doubling time $(\mathrm{Tt})$ & 2.87 & 3.96 & 4.30 & 4.98 & 5.02 & 5.17
\end{tabular}

dry biomass (Table 2). The algal biomass production and $\mathrm{NaCl}$ concentration are negatively correlated each other in such a way that there was an increment in the biomass production observed at lower $\mathrm{NaCl}$ concentrations.

The Chlorella showed the maximum biomass content of about $1.021 \mathrm{~g} / \mathrm{L}$ under $0.2 \mathrm{M} \mathrm{NaCl}$ concentrations. Similar effects were also observed in Chlamydomonas mexicana and Scenedesmus obliquus (Salama et al., 2013; Mohan and Devi, 2014). In contrast, the biomass yield was increased in the salinity stress, i.e., 17-34 $\mathrm{mM}$ in green microalgae, Botryococcus braunii, was also reported (Rao et al., 2007).

\section{Influence of Salt Stress on Lipid in S. quadricauda}

The maximum lipid yield was observed at 20th day in salt-treated cells compared to control. But the algal growth was slightly inhibited at higher $\mathrm{NaCl}$ concentration ( 40 and $50 \mathrm{mM}$ ). The total lipid yield was increased in 30, 40, $50 \mathrm{mM} \mathrm{NaCl}$-treated cultures (191 and $205 \mathrm{mg} / \mathrm{L})$ compared to control $(118 \mathrm{mg} / \mathrm{L})$ on 15 th day (Figure 3). As the trend, the lipid yield was also found to be increased in higher concentration on 20th day. It was about 208, 195 , and $201 \mathrm{mg} / \mathrm{L}$ in 30, 40, and $50 \mathrm{mM}$, respectively (Figure 3). It was also further confirmed by TLC with appropriate standard for TAG (Supplementary Image 1).

Similarly, the total lipid content increased under higher salt concentration in Dunaliella were reported by Takagi et al. (2006), and it is possibly due to the cells adapted to the stress condition and accumulation of more lipids. The higher concentration may

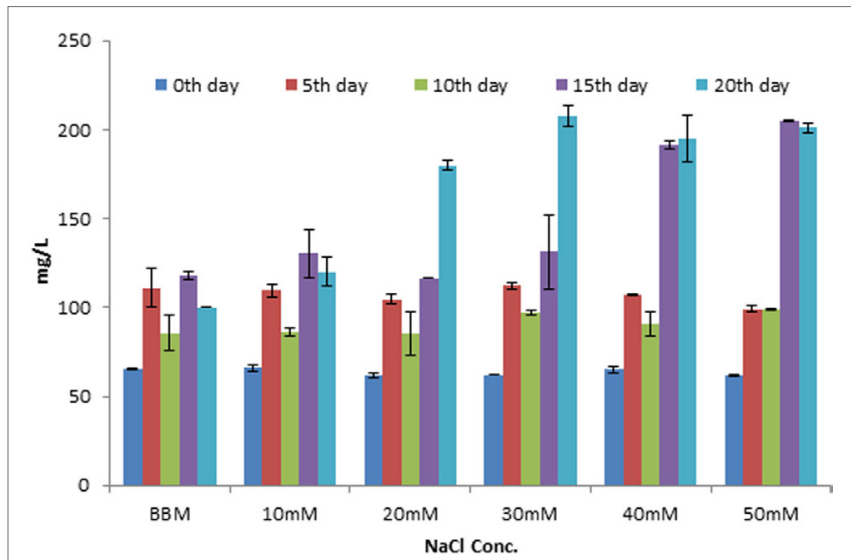

FIGURE 3 | Estimation of total lipid content in Scenedesmus quadricauda in different salt stress condition.

TABLE 2 | Biomass content of S. quadricauda under different salt stress condition.

\begin{tabular}{|c|c|c|c|c|c|}
\hline & Oth day & 5th day & 10th day & 15th day & 20th day \\
\hline BBM & $21.5 \pm 1.5$ & $48.0 \pm 1.0$ & $109.7 \pm 3.1$ & $146.29 \pm 2.3$ & $236.61 \pm 3.2$ \\
\hline $10 \mathrm{mM}$ & $19.5 \pm 1.5$ & $35.0 \pm 3.0$ & $78.95 \pm 3.6$ & $118.07 \pm 3.7$ & $178.61 \pm 1.6$ \\
\hline $20 \mathrm{mM}$ & $21.5 \pm 1.5$ & $32.5 \pm 2.3$ & $71.75 \pm 3.2$ & $99.8 \pm 1.8$ & $145.96 \pm 2.6$ \\
\hline $30 \mathrm{mM}$ & $22.5 \pm 1.5$ & $32.75 \pm 0.7$ & $67.75 \pm 1.5$ & $90.3 \pm 2.3$ & $148.10 \pm 1.8$ \\
\hline 40mM & $20.0 \pm 1.0$ & $30.8 \pm 2.2$ & $54.15 \pm 1.8$ & $82.81 \pm 3.1$ & $138.26 \pm 2.2$ \\
\hline $50 \mathrm{mM}$ & $20.0 \pm 0.0$ & $29.5 \pm 0.5$ & $48.38 \pm 0.61$ & $81.5 \pm 1.5$ & $129.5 \pm 0.5$ \\
\hline
\end{tabular}


mediate lipid accumulation by nutrient starvation. And also, the algal cells incubated under saline condition for a longer time period revealed an enhancement in the lipid accumulation within the stressed algal cells. During salt stress condition, pronounced variation in $\mathrm{pH}$, TDS, salinity, and conductivity were observed in Scenedesmus (Supplementary Table 1). According to Rao et al. (2007), the $\mathrm{pH}$ of the algal cells varies with respect to salt concentration in green microalgae $B$. braunii.

\section{Influence of Salt Stress on Photosynthetic Pigment in S. quadricauda}

The similar pattern of decrease in photosynthetic pigment was also seen in different $\mathrm{NaCl}$ concentration. The total photosynthetic pigment level varies gradually viz Chl-a, Chl-b, carotenoids $(0.110 \pm 0.01,0.065 \pm 0.02,0.069 \pm 0.00 \mathrm{mg} / \mathrm{L})$ in $50 \mathrm{mM}$ $\mathrm{NaCl}$ concentration on 20th day (Table 3 ). The photosynthetic pigments in salt-treated algal cells $(50 \mathrm{mM})$ showed that there is a reduction from 0.377 (Control) to $0.110 \mathrm{~g} / \mathrm{L}$ of Chl-a on the 20th day of stress. Also, the similar trend was observed with chlorophyll $\mathrm{b}$ and carotenoids during salt stress.

There was a report suggesting that the reduction in photosynthetic rate is directly proportional to that of reduction in the growth rate of microalgae (Ben-Amotz et al., 1985). The salt tolerance studies in Chlorella sp. showed that they can tolerate the lower $\mathrm{NaCl}$ concentration, and it can grow same as normal cells, but with an increased $\mathrm{NaCl}$ concentration revealed degradation of chlorophyll, and it leads to cell death (Salama et al., 2013; Mohan and Devi, 2014). Thus, an optimum $\mathrm{NaCl}$ concentration is required for the normal growth of microalgae, higher or lower concentration of salt concentration leads to a decrement in their growth rate (Takagi et al., 2006; Ruangsomboon, 2012).

\section{Influence of Salt Stress in Fatty Acid Analysis of S. quadricauda}

The fatty acid composition of $S$. quadricauda under salt stress revealed that there is a marked difference in the saturated: monounsaturated fatty acid composition. The gas chromatogram of control showed that about $79.2 \%$ of saturated and $20.8 \%$ monounsaturated fatty acids (Figure 4). But salt-treated (50 mM) has about $59.2 \%$ of saturated fatty acids, i.e., $20 \%$ reduction in saturated fatty acid level. Also, the monounsaturated level is $40.7 \%$ which is about $19.9 \%$ increment in monounsaturated fatty acids (Figure 4; Supplementary Image 2).

Here, the FAME composition reveals that the altered fatty acid profile is an appropriate proportion for biofuel production. Also, we can mix appropriate proportion of sea water to the media to cultivate the algae in defined concentration, which makes a reduction in biomass production cost and decreases the

TABLE 3 | Photosynthetic pigment content of S. quadricauda under salt stress.

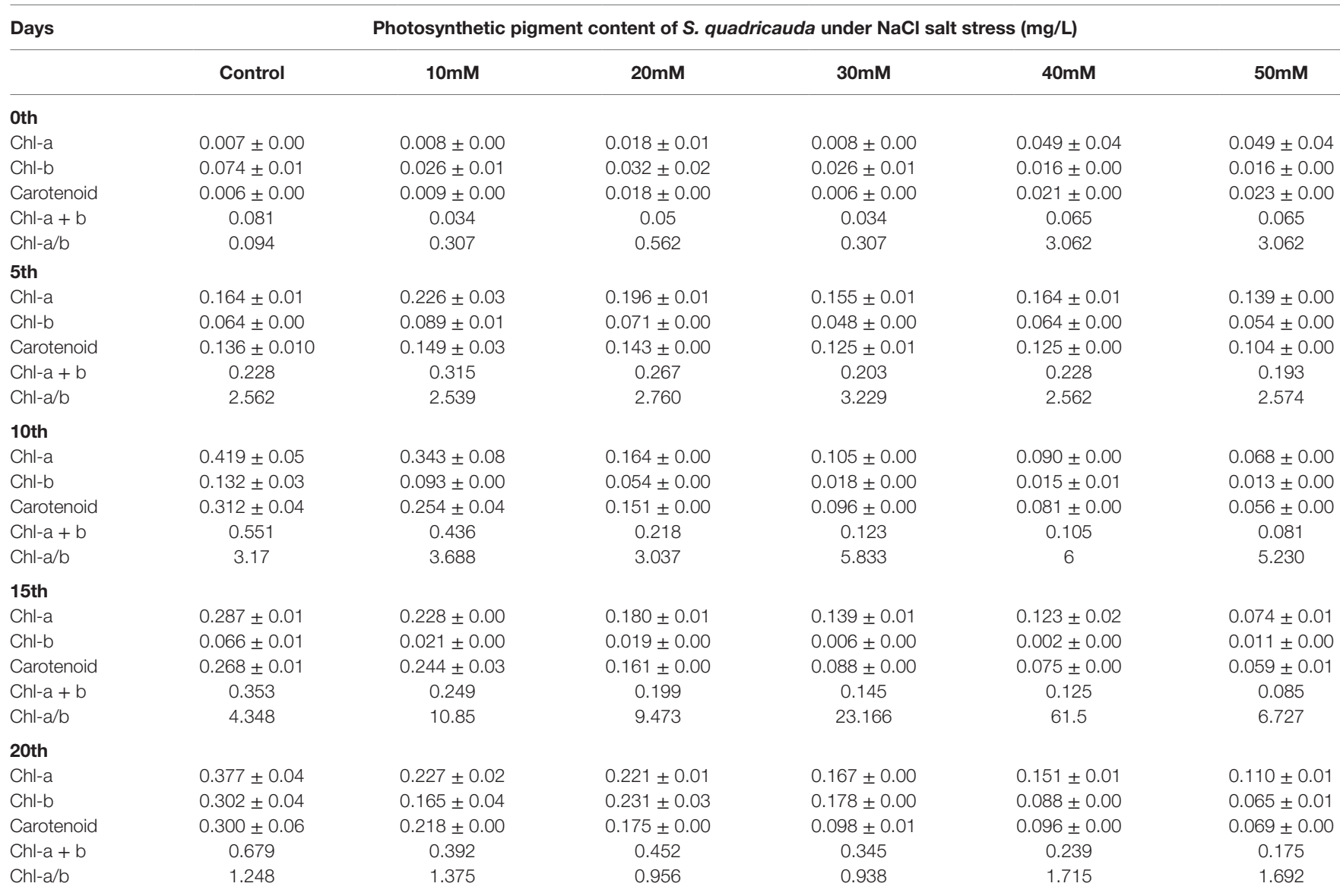



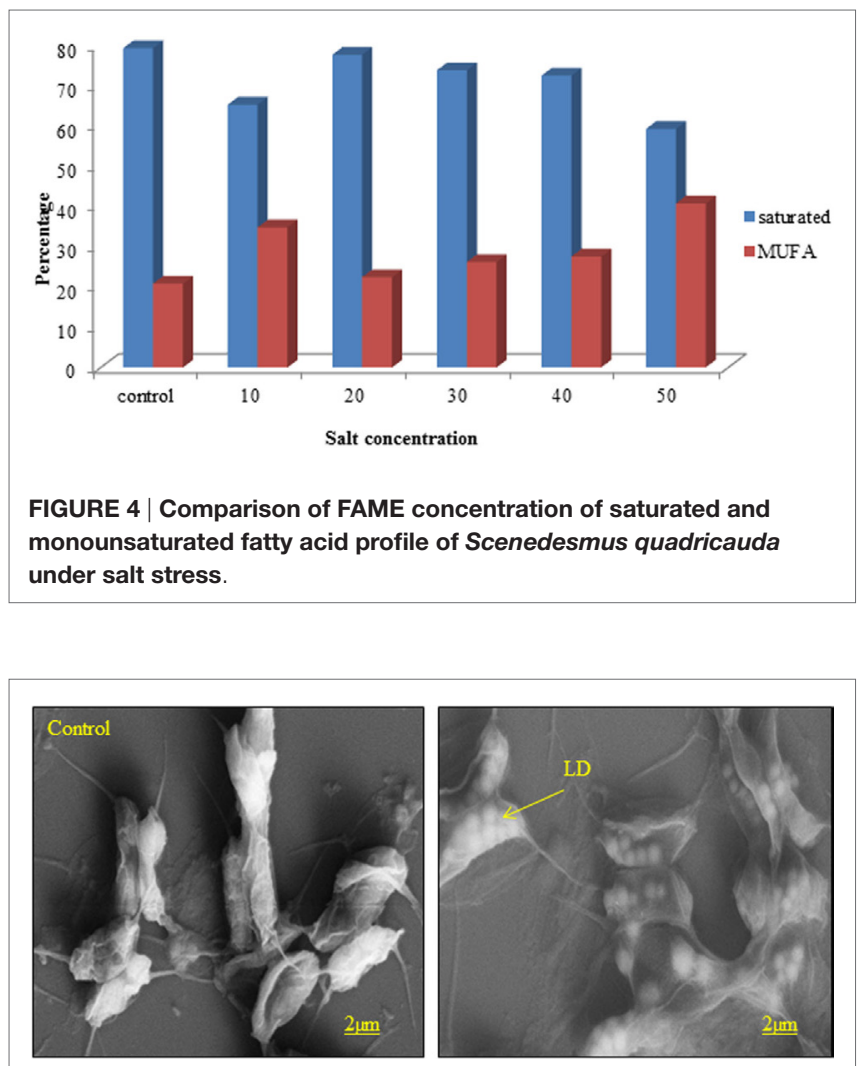

FIGURE 5 | Scanning electron microscope images of S. quadricauda under salt stress condition (LD) lipid droplet. Scale bars represent $2 \mu \mathrm{m}$ size.

fresh water requirement for algal cultivation. Abundant availability of seawater can be used for algal cultivation with biofuel application. According to Rao et al. (2007), the presence of monounsaturated and polyunsaturated fatty acids was detected in $B$. braunii during salt stress with palmitoleic and oleic acids as major fatty acids.

\section{Influence of Salt Stress in SEM Analysis of S. quadricauda}

A time course LD formation during nitrogen-starved condition was performed in C. reinhardtii (Moellering and Benning, 2010). The results reveal that first LD was observed at $12 \mathrm{~h}$ of $\mathrm{N}$ deprivation, followed by the number as well as the large size

\section{REFERENCES}

Anand, J., and Arumugam, M. (2015). Enhanced lipid accumulation and biomass yield of Scenedesmus quadricauda under nitrogen starved condition. Bioresour. Technol. 188, 190-194. doi:10.1016/j.biortech.2014.12.097

Athenstaedt, K., and Daum, G. (2006). The life cycle of neutral lipids: synthesis, storage and degradation. Cell. Mol. Life Sci. 63, 1355-1369. doi:10.1007/ s00018-006-6016-8

Ben-Amotz, A., Tornabene, T. G., and Thomas, W. H. (1985). Chemical profile ofselected species of microalgae with special emphasis on lipids. J. Phycol. 21, 72-81. doi:10.1111/j.0022-3646.1985.00072 of LDs formed during 24 or $48 \mathrm{~h}$ of $\mathrm{N}$ deprivation (Moellering and Benning, 2010). In the present study, we also observed an LD-like structure in scanning electron microscopy shows (Figure 5) more lipid body formation in higher $\mathrm{NaCl}$ concentration $(50 \mathrm{mM})$, such structure was not observed in cells grown in normal condition.

The previous reports describe that the Chlamydomonas wild and mutant has accumulated more storage lipid bodies inside the cell by an external environmental factor (Li et al., 2010). In the green microalgae, C. minutissima shows in the oil body formation in environmental stress factors (Wang et al., 2011).

\section{CONCLUSION}

Presence of major LD protein was detected in S. quadricauda in salt stress and nitrogen-starved condition. Thus, the MLDP is highly conserved in green algae, and the size and number are increased during the abiotic stress condition like nitrogen starvation and salt stress. Conclusively, MLDP-like protein can be used as a marker for stress-mediated lipid accumulation during abiotic stress.

\section{AUTHOR CONTRIBUTIONS}

Design and plan of experiments: MA. Performed the experiments: AJ, SS, and SP. Analyzed the data: MA, SS, and AJ. Contributed reagents: Dr. Anthony Huang. Wrote the paper: MA, SS, and JA.

\section{FUNDING}

The work was supported by the grant from DST-SERB, Government of India through the fast track project entitled "SB/ YS/LS-13/2013": "Biochemical and Molecular investigation on stress-mediated lipid accumulation and biomass productivity in microalgae" to MA. We are thankful to Dr. Anthony Huang of Institute of Plant and Microbial Biology, University of California, Riverside for providing MLDP antibody. We are also grateful to Dr. R. Arumugam for confocal imaging at Rajiv Gandhi Centre for Biotechnology, Trivandrum, India.

\section{SUPPLEMENTARY MATERIAL}

The Supplementary Material for this article can be found online at http://journal.frontiersin.org/article/10.3389/fenrg.2016.00037/ full\#supplementary-material.

Brown, D. A. (2001). Lipid droplets: proteins floating on a pool of fat. Curr. Biol. 11, R446-R449. doi:10.1016/S0960-9822(01)00257-3

Cristie, W. W. (1982). Lipid Analysis, Isolation, Separation, Identification and Structural Analysis of Lipids. Oxford: Pregamon Press.

Davidi, L., Katz, A., and Pick, U. (2012). Characterization of major lipid droplet proteins from Dunaliella. Planta 236, 19-33. doi:10.1007/s00425-011-1585-7

Folch, J., Lees, M., and Sloane-Stanley, G. (1957). A simple method for the isolation and purification of total lipids from animal tissues. J. Biol. Chem. 226, 497-509.

Guermeur, Y., Paugam-Moisy, H., and Gallinari, P. (1998). "Multivariate linear regression on classifier outputs: a capacity study," in ICANN98 (London: Springer), 693-698. 
Guillard, R. R. L., and Ryther, J. H. (1962). Studies on marine planktonic diatoms I. Cyclotella nana Hustedt and Detonulaconfervacea (Cleve) Gran. Can. J. Micro. 8, 229-239. doi:10.1139/m62-029

Huang, A. H. (1992). Oil bodies and oleosins in seeds. Ann. Rev. Plant Physiol. 43, 177-200. doi:10.1146/annurev.pp.43.060192.001141

Huang, C. N., Huang, M. D., Chen, T. L., and Huang, A. H. (2013). Oleosin of subcellular lipid droplets evolved in green algae. Plant Physiol. 161, 1862-1874. doi:10.1104/pp.112.212514

Hyder, S. Z., and Greenway, H. (1965). Effects of $\mathrm{Ca}^{++}$on plant sensitivity to high $\mathrm{NaCl}$ concentrations. Plant Soil 23, 258-260. doi:10.1007/BF01358351

James, G. O., Hocart, C. H., Hillier, W., Chen, H., Kordbacheh, F., Price, G. D., et al. (2011). Fatty acid profiling of Chlamydomonas reinhardtii under nitrogen deprivation. Bioresour. Technol. 102, 3343-3351. doi:10.1016/j.biortech.2010.11.051

Li, Y., Han, D., Hu, G., Dauvillee, D., Sommerfeld, M., Ball, S., et al. (2010). Chlamydomonas starchless mutant defective in ADP-glucose pyrophosphorylase hyper-accumulates triacylglycerol. Metab. Eng. 12, 387-391. doi:10.1016/j. ymben.2010.02.002

Lichtenthaler, H. K. (1987). "Chlorophylls and carotenoids, the pigments of photosynthetic biomembranes," in Methods Enzymol, Vol. 148, eds R.Douce and L.Packer (New York, NY: Academic Press Inc.), 350-382.

Marinkovic, S. S., and Tomasevic, A. (1998). Transesterification of sunflower oil in situ. Fuel 77, 1389-1391. doi:10.1016/S0016-2361(98)00028-3

Moellering, E. R., and Benning, C. (2010). RNA Interference silencing of a major lipid droplet protein affects lipid droplet size in Chlamydomonas reinhardtii. Eukaryot. Cell 9, 97-106. doi:10.1128/EC.00203-09

Mohan, S. V., and Devi, M. P. (2014). Salinity stressinduced lipid synthesis to harness biodiesel duringdual mode cultivation of mixotrophicmicroalgae. Bioresour. Technol. 165, 288-294. doi:10.1016/j.biortech.2014.02.103

Murphy, W. J., Eizirik, E., O’Brien, S. J., Madsen, O., Scally, M., Douady, C. J., et al. (2001). Resolution of the early placental mammal radiation using Bayesian phylogenetics. Science 294, 2348-2351. doi:10.1126/science.1067179

Nguyen, H. M., Baudet, M., Cuine, S., Adriano, J. M., Barthe, D., Billon, E., et al. (2011). Proteomic profiling of oil bodies isolated from the unicellular green microalga Chlamydomonas reinhardtii: with focus on proteins involved in lipid metabolism. Proteomics 11, 4266-4273. doi:10.1002/pmic.201100114

Peled, E., Leu, S., Zarka, A., Weiss, M., Pick, U., Khozin-Goldberg, I., et al. (2011). Isolation of a novel oil globule protein from the green alga Haematococcus pluvialis (Chlorophyceae). Lipids 46, 851-861. doi:10.1007/s11745-011-3579-4

Rao, A. R., Dayananda, C., Sarada, R., Shamala, T. R., and Ravishankar, G. A. (2007). Effect of salinity on growth of green alga Botryococcus braunii and its constituents. Bioresour. Technol. 98, 560-564. doi:10.1016/j.biortech.2006.02.007

Ruangsomboon, S. (2012). Effect of light, nutrient, cultivation time and salinity on lipid production of newly isolated strain of the green microalga, Botryococcus braunii KMITL 2. Bioresour. Technol. 109, 261-265. doi:10.1016/j. biortech.2011.07.025

Salama, E. S., Kim, H. C., Abou-Shanab, R. A., Ji, M. K., Oh, Y. K., Kim, S. H., et al. (2013). Biomass, lipid content, and fatty acid composition of freshwater Chlamydomonas mexicana and Scenedesmus obliquus grown under salt stress. Bioprocess Biosyst. Eng. 36, 827-833. doi:10.1007/s00449-013-0919-1
Schmidt, M. A., and Herman, E. M. (2008). Suppression of soybean oleosin produces micro-oil bodies that aggregate into oil body/ER complexes. Mol. Plant 1, 910-924. doi:10.1093/mp/ssn049

Siloto, R. M., Findlay, K., Lopez-Villalobos, A., Yeung, E. C., Nykiforuk, C. L., and Moloney, M. M. (2006). The accumulation of oleosins determines the size of seed oil bodies in Arabidopsis. Plant Cell 18, 1961-1974. doi:10.1105/ tpc.106.041269

Su, C.-H., Chien, L.-J., Gomes, J., Lin, Y. S., Yu, Y. K., Liouand, J. S., et al. (2011). Factors affecting lipid accumulation by Nannochloropsis oculata in a two-stage cultivation process. J. Applphycol. 23, 903-908. doi:10.1007/s10811010-9609-4

Sulochana, S. B., and Arumugam, M. (2016). Influence of abscisic acid on growth, biomass and lipid yield of Scenedesmus quadricauda under nitrogen starved condition. Bioresour. Technol. 213, 198-203. doi:10.1016/j.biortech.2016. 02.078

Takagi, M., Karseno, Y., and Yoshida, T. (2006). Effect of salt concentration on intracellular accumulation of lipids and triacylglyceride in marine microalgae Dunaliella cells. J. Biosci. Bioeng. 101, 223-226. doi:10.1263/jbb.101.223

Talebi, A. F., Tabatabaei, M., Mohtashami, S. K., Tohidfar, M., and Moradi, F. (2013). Comparative salt stress study on intracellular ion concentration in marine and salt-adapted freshwater strains of microalgae. Not. Sci. Biol., 5, 309-315. doi:10.15835/nsb.5.3.9114

Tsai, C. H., Warakanont, J., Takeuchi, T., Sears, B. B., Moellering, E. R., and Benning, C. (2014). The protein compromised hydrolysis of triacylglycerols 7 (CHT7) acts as a repressor of cellular quiescence in Chlamydomonas. Proc. Natl. Acad. Sci. U.S.A 111, 15833-15838. doi:10.1073/pnas.1414567111

Wang, S. T., Pan, Y. Y., Liu, C. C., Chuang, L. T., and Chen, C. N. N. (2011). Characterization of a green microalga UTEX 2219-4: effects of photosynthesis and osmotic stress on oil body formation. Bot. Stud. 52, 305-312.

Xin, L., Hong-yingand, H., and Yu-ping, Z. (2011). Growth and lipid accumulation properties of a freshwater microalga Scenedesmus sp. under different cultivation temperature. Bioresour. Technol. 102, 3098-3102. doi:10.1016/j. biortech.2010.10.055

Zweytick, D., Leitner, E., Kohlwein, S. D., Yu, C., Rothblatt, J., and Daum, G. (2000). Contribution of Arelp and Are2p to steryl ester synthesis in the yeast Saccharomyces cerevisiae. Eur. J. Biochem. 267, 1075-1082. doi:10.1046/ j.1432-1327.2000.01103

Conflict of Interest Statement: The authors declare that the research was conducted in the absence of any commercial or financial relationships that could be construed as a potential conflict of interest.

Copyright $\odot 2016$ Javee, Sulochana, Pallissery and Arumugam. This is an open-access article distributed under the terms of the Creative Commons Attribution License (CC $B Y)$. The use, distribution or reproduction in other forums is permitted, provided the original author(s) or licensor are credited and that the original publication in this journal is cited, in accordance with accepted academic practice. No use, distribution or reproduction is permitted which does not comply with these terms. 